\title{
A Educación Global na Educación Secundaria Obligatoria: unha investigación diagnóstica nos centros educativos de Galicia
}

\section{Global Education in Secondary Education: diagnostic investigation with schools in Galicia}

\author{
Araceli Serantes*, Renée DePalma*, M. Dolores Cotelo*, José Luis Iglesias*, Patricia Digón*, Begoña Rivera*, Carmen \\ Becerra*, María Caride** e Ana Lampón** $^{* *}$ \\ *Grupo de Investigación Política Educativa, Historia e Sociedade - UDC; **Solidariedade Internacional de Galicia
}

\begin{abstract}
Resumen
O proxecto de investigación colaborativa "Explo- rando as posibilidades de estender a dimensión global da educación para o desenvolvemento na ESO. Unha investigación diagnóstica en centros educativos" realízase entre o GI "Política Educativa, Historia e Sociedade" da UDC e Solidariedade Internacional de Galicia, financiado pola Xunta de Galicia. O obxectivo é identificar as necesidades do profesorado e do centro educativo para integrar a perspectiva da Educación Global no curriculum. Pártese da experiencia do Reino Unido, de persoas expertas e do profesorado galego para proporcionar aos docentes descripciones e recursos que permitan integrar esta dimensión nas aulas.
\end{abstract}

\begin{abstract}
The collaborative research project "Exploring the possibilities of extending the global dimension of Education for Development in the ESO. Diagnostic investigation in the schools" is conducted between the GI "Education Policy, History and Society" of the UDC and Solidariedade International of Galician, funded by the Xunta de Galicia. The aim is to identify the needs of teachers and the school for mainstreaming Global Education in the curriculum. We started from the experience of UK, experts and Galician teachers to provide descriptions and resources for teachers to integrate this dimension in the classroom.
\end{abstract}

Palabras chave: Educación para o desenvolvemento, educación global, investigación cualitativa, ensinanza secundaria obligatoria

Keywords: Development education, global education, qualitative research, compulsory secondary education

\section{Introdución}

O proxecto "Explorando as posibilidades de estender a dimensión global da EpD na Educación Secundaria Obrigatoria. Unha investigación diagnóstica en centros educativos de Galicia” (PR804A2014/07) é unha proposta de investigación colaborativa entre a ONGD Solidariedade Internacional de Galicia (SI-G) e membros do Grupo de Investigación "Política Educativa, Historia e Sociedade" da Facultade de Ciencias da Educación da Universidad da Coruña, que conta cunha subvención de Vicepresidencia e Consellería de Presidencia,
Administracións Públicas e Xustiza da Xunta de Galicia, a través da Axencia de Cooperación Galega, en réxime de concurrencia competitiva.

O obxectivo é identificar as necesidades do profesorado e do centro educativo que colabora nos proxectos de Educación para o Desenvolvemento (EpD) promovidos polas ONGDs, para que estas accións sexan máis significativas para o alumnado.

$\mathrm{O}$ proxecto ten catro partes ben diferenciadas, con obxectivos concretos, que permitirán triangular a información de cara a facer propostas máis achegadas (Gráfico 1):

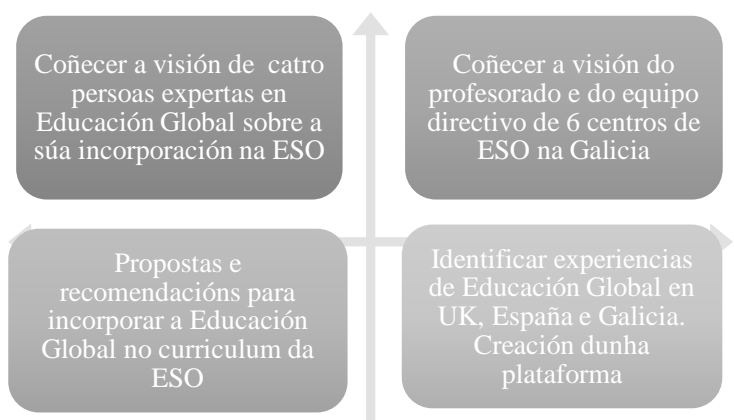

Gráfico 1. Partes da investigacıón

1. Identificación, análise e selección de materiais curriculares sobre Educación Global deseñados no Reino Unido Development Education Research Center do Instituto de Educación da UCL. Identificación, análise e selección de materiais curriculares deseñados a nivel estatal e galego sobre Educación Global.

2. Análise da experiencia, expectativas e visión do profesorado e dos equipos directivos de 6 centros galegos da ESO que teñan participado en programas e actividades con SI-G.

3. Análise das aportacións de alomenos catro personas de recoñecido prestixio no ámbito da EpD e da Educación Global.

4. Propostas e recomendacións para poder incorporar a dimensión global no curriculum da ESO.

Tomamos como referencia o primeiro documento que data do ano 2000, no que emerxe a denominada

Proxecto de Investigación "Explorando as posibilidades de estender a dimensión global da educación para o desenvolvemento na ESO. Unha investigación diagnóstica en centros educativos” financiado a través da Cooperación Galega da Xunta de Galicia (PR804A 2014/07).

Correspondencia: A. Serantes, boli@udc.es; R. DePalma, r.depalma@udc.es; MD. Cotelo, mcotelo@udc.es; JL Iglesias, jiglesias@udc.es; P. Digón pdigon@udc.es; B. Rivera begona.rivera@udc.es; MC. Becerra carmen.becerra@udc.es; M. Caride sensibilizacion@solidaridadgalicia.org; A. Lampón educación@solidaridadgalicia.org; 
“Dimensión Global” (Bourn \& Hunt, 2011). Analizáronse os traballos do Development Education Research Center do Instituto de Educación da UCL dirixido por Douglas Bourn.

\section{Metodoloxía da investigación}

O deseño corresponde a unha investigación de carácter polimetodolóxico de corte cualitativo, no que se utilizaron diferentes técnicas que permitiron comprender as experiencias sociais nos escenarios naturais, desde a perspectiva dos protagonistas (neste caso o profesorado) (Grotjahn, 1991). Pódense identificar 5 momentos (Gráfico 2):

1. Análise de documentos para caracterizar a dimensión global no curriculo e nas propostas didácticas do Reino Unido. Análise das distintas fontes documentais organizando o contido en unidades de significado a través dun método indutivo para a elaboración de categorías (Miles \& Huberman, 1994)

2. Microestudos de caso en 6 centros educativos para coñecer os intereses e necesidades do profesorado individualmente e do centro no seu conxunto, mediante entrevistas -de corte narrativo e semiestructuradas- a tres tipos de informantes (membros do equipo directivo, responsables das bibliotecas e profesorado que xa desenvolveu actividades de EpD con SI-G nas aulas) (Simons, 2006).

3. Grupos focais para contrastar as distintas realidades dos centros educativos e contrastar posicionamentos de forma simultánea (Onwuegbuzie, Dickinson, Leech \& Zoran, 2011).

4. Entrevistas semiestructuradas a persoas expertas en Educación Global (Kvale, 2011; Valles, 2014).

5. Elaboración de forma colaborativa dunha plataforma dixital.

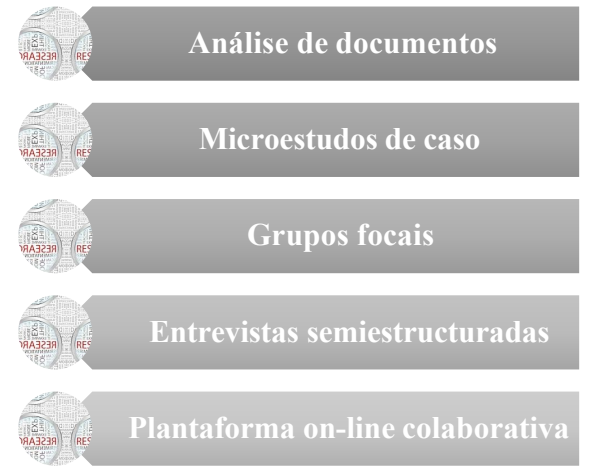

Gráfico 2. Técnicas utilizadas na investigación

Como estratexia xeral de análise aplicouse a codificación temática, ao trátase dunha investigación de corte cualitativo, que busca describir as diferentes maneras nas que o profesorado comprometido cos proxectos de EpD dotan de significado a obxectos, acontecementos e experiencias relacionadas coa EpD e a Educación Global no seu centro, y que constitúen o punto central da investigación (Flick, 2012).

Para asegurar a fiabilidade da investigación fumos documentando todo o proceso. Optamos por diversificar fontes e informantes, e posteriormente á triangulación de resultados (Stake, 1998). Recurrimos á retroalimentación cos participantes para validar as transcripcións das entrevistas e realizamos un Grupo Focal para a confrontación de pareceres. Presentamos a plataforma nos centros para rematar de forma colaborativa o producto que vai transcender a propia investigación (Onwuegbuzie, Dickinson, Leech \& Zoran, 2011).

A ética da investigación respectase mediante o contraste da información cos participantes durante todo o proceso. Respéctase tamén a confidencialidade e anonimato dos docentes e centros.

A finalidade da investigación é proporcionar descripcións e interpretacións que axuden aos docentes a introducir a dimensión global da educación nas aulas, e non xeralizacións. Trátase de amosar visións susceptibles de provocar xeralizacións naturalísticas (Stake, 1998) que posibiliten a outros docentes aplicar aspectos das nosas achegas.

\section{Contexto no que se enmarca a investigación}

Para as ONGDs, o ámbito escolar é un campo de actuación chave que facilita o desenvolvemento de programas de EpD co alumnado, o profesorado e a comunidade educativa, porén existe unha grande dificultade en acadar unha colaboración permanete (Beamish, Bryer \& Davies, 2006; Montero, 2011) o que se traduce na práctica en intervencións de carácter puntual, e introducidas nos contidos dunha materia. Estes mesmos condicionantes foron postos de manifesto polas achegas acadadas pola nosa primeira investigación "Investigando na Educación para o Desenvolvemento. Un estudio de caso sobre a implementación do proxecto do Tesouro de Acahualinca", investigación financiada pola Xunta de Galicia no marco do II Plan Director de Cooperación para o Desenvolvemento de Galicia (2010-2013).

As proncipais achegas da primeira investigación amosan que:

- As materias implicadas nos proxectos de EpD son preferentemente de corte social e menos "académicas" con pouca carga lectiva (Ética, Educación para a cidadanía, Relixión con contidos relacionados coa formación democrática e os dereitos humanos. Esta cualidade dificulta a continuidade das intervencións e limita a súa profundidade.

- Unha profesora de Ciencias Sociais revela o potencial que proxectos de EpD teñen para materias máis académicas.

- Os estudantes que participaron manifestan verbal e comportamentalmente a súa preferencia por metodoloxías participativas, experienciais e creativas, máis vinculadas a procesos e destrezas de aprendizaxe e menos a contidos. Esto require máis tempo e implicación por parte do profesorado, no sentido de incluír as tarefas do proxecto na dinámica curricular da materia e apoiar o traballo dos estudantes están revelándose chaves para acadar os obxectivos formativos do proxecto de EpD investigado.

- A entrada da Epd no sistema educativo prodúcese xeralmente a través da promoción da competencia social e cidadá e non é tratada de xeito transversal polas diferentes materias. Autores como Aguado (s/d), Polo (2004) ou Paz (2007) presenta como vincular a Educación Global á vida do centro educativo e á ensinanza das materias. 
Debido ao carácter globalizado das nosas sociedades, urxe promover saberes e prácticas cidadás que garantan a convivencia e a cohesión social desde o respecto aos dereitos e liberdades cidadás. A ensinanza dos valores da liberdade, igualdade e tolerancia nunha cidadanía activa e comprometida coa democracia e os dereitos humanos require de aprendizaxes, destrezas e actitudes especificamente enfocadas a comprender e actuar nun mundo interdependente e multicultural. Por esta razón, nos países da nosa contorna están a introducir no currículo oficial o ensino da Educación global (Hicks \& Holden, 2007; Bourn, 2008; Edge, Khamsi e Bourn, 2009; Bourn \& Hunt, 2011). A Educación Global é outro modo de falar da EpD, directamente ligado á EpD de $5^{a}$ xeración, cuxa principal aspiración é contribuír a crear unha cidadanía global, activa e comprometida coa democracia, a xustiza social e os dereitos humanos (Argibay, Celorio \& Celorio, 2009; Canarias \& Altamira, 2012). Esta visión da EpD constrúese a partir da noción de cidadanía cosmopolita (Nussbaum, 2005), tamén denominada cidadanía global.

Cuestións relacionadas co desenvolvemento e a dimensión global foron traballadas durante anos en centros de educación secundaria ingleses en materias como xeografía, ciencias ou historia, así como de forma transversal en actividades do centro educativo relacionadas con proxectos de ONGs e ONGDs . Desde 1997 a educación para o desenvolvemento comezou a ter apoio desde o goberno creándose o DFID (Department for Intenational Development) e desde o 2000 en diante a dimensión global pasou a formar parte das guías curriculares creadas desde o Departamento de Educación (Bourn \& Hunt, 2011). Segundo a Declaración de Maastrich sobre Educación Global (CEEG, 2002) a dimensión global engloba oito dimensións: (i) educación para o desenvolvemento, (ii) educación en Dereitos Humanos, (iii) educación para a sostenibilidade, (iv) Educación para a paz e prevención de conflictos, e (v) educación intercultural; e interdependencia. Tendo en conta este carácter aglutinador, probablemente froito do interese por facilitar a súa inserción non currículo, poden botarse en falla algunhas temáticas coma a educación para igualdade e coeducación; o que pon de manifesto o interese de analizar estas proposta dun xeito crítico, co fin de valorar a súa posibilidade de extrapolación.

Este traballo enmárcase no marco da LOE (2/2006), mais tanto esta lei xeral de educación, como a presente LOMCE (8/2013), sinalan que o alumnado debe asumir responsablemente os seus deberes, coñecer e exercer os seus dereitos, practicar a tolerancia, a cooperación e a solidariedade, e exercitarse no diálogo, afianzando os dereitos humanos como valores comúns dunha sociedade plural e preparándose para o exercicio da cidadanía democrática.

Con esta investigación colaborativa queremos, xa que logo, afondar nunha senda xa aberta apuntalando a relación entre o mundo académico e o mundo da práctica da EpD, para xerar coñecemento dun xeito sistemático.

\section{Formulación e proceso da investigación}

O obxectivo do proxecto é de carácter diagnóstico e propositivo. Por unha banda búscase explorar as perspectivas do profesorado respecto da relación entre a súa materia e o mundo global e interdependente no que vivimos, para amosar o vínculo entre os contidos habituais e as aprendizaxes e destrezas que require a dimensión global. Por outra banda, interésanos abordar as peculiaridades dos centros educativos que xa teñen profesorado colaborando en Proxectos de EpD con SI-G, para estudar a súa cultura de centro e a súa identidade pedagóxica. Con este estudo buscamos formular xeitos de abordar a presenza da dimensión global en futuros proxectos de EpD, ofrecendo ás áreas máis académicas un abano máis amplo de competencias e aprendizaxes, e apoiando un traballo máis interdisciplinario e significativo para o conxunto do centro. Sería un modo de ir facilitando a introdución da educación global na escola, tal e como é entendida a nivel internacional (Marshall, 2007; Bourn e Hunt, 2011; Andreotti, 2012; Ruíz \& Celorio, 2012) .

Indagar sobre a formulación da dimensión global na educación formal do Reino Unido e explorar a permeabilidade das materias da ESO para incluíla no curriculum pode axudar na resolución do desafío persistente de non quedar nunha acción puntual. Descubrir os intereses, necesidades e perspectivas do profesorado e a identidade dos centros educativos de secundaria é un modo de promover accións idiosincrásicas que facilitan a superposición da EpD sobre as prácticas xa existentes, e a vincula á identidade do centro. Este modo de traballo facilita a recombinación creativa, un modo de innovación que se apoia no legado pedagóxico dos centros educativos (Hargreaves e Fink, 2008).

Respecto ao proceso de investigación, diferenciamos cinco etapas diferenciadas en canto a obxectivos, contidos e métodos (Táboa 1).

Táboa 1. Etapas da investigación

\begin{tabular}{|l|l|l|}
\hline \multicolumn{1}{|c|}{ ETAPA } & \multicolumn{1}{|c|}{ OBXECTIVO } & \multicolumn{1}{c|}{ TÉCNICAS } \\
\hline $\begin{array}{l}\text { Revisión de } \\
\text { literatura } \\
\text { especializada e } \\
\text { documentos do UK }\end{array}$ & $\begin{array}{l}\text { Coñecer } \\
\text { experiencias e o } \\
\text { tratamento da } \\
\text { Educación Global }\end{array}$ & $\begin{array}{l}\text { Análise de } \\
\text { documentos } \\
\text { Análise de contidos }\end{array}$ \\
\hline $\begin{array}{l}\text { Realización das } \\
\text { entrevistas a } \\
\text { expertos }\end{array}$ & $\begin{array}{l}\text { Coñecer seu punto } \\
\text { de vista respecto á } \\
\text { EG }\end{array}$ & $\begin{array}{l}\text { Entrevistas } \\
\text { semiestructuradas } \\
\text { Análise de contidos }\end{array}$ \\
\hline $\begin{array}{l}\text { Realización de } \\
\text { entrevistas ao } \\
\text { profesorado }\end{array}$ & $\begin{array}{l}\text { Coñecer como } \\
\text { integran a EG nas } \\
\text { materias e no centro }\end{array}$ & $\begin{array}{l}\text { Entrevistas de corte } \\
\text { narrativo } \\
\text { Grupos Focais } \\
\text { Análise de contidos }\end{array}$ \\
\hline Cruzado de datos & Descripción de datos & $\begin{array}{l}\text { A modo de estudo } \\
\text { múltiple }\end{array}$ \\
\hline $\begin{array}{l}\text { Plataforma virtual de } \\
\text { EG }\end{array}$ & $\begin{array}{l}\text { Facilitar o acceso a } \\
\text { documentos, } \\
\text { recursos e } \\
\text { experiencias }\end{array}$ & $\begin{array}{l}\text { Catalogación según } \\
\text { criterios } \\
\text { Colaboración do } \\
\text { profesorado }\end{array}$ \\
\hline
\end{tabular}




\section{Avance dos resultados}

Analizáronse en profundidade os documentos dispoñibles en Development Education Research Centre (DERC) (http://www.ioe.ac.uk/research/150.html), así como os Curriculos Nacionais de Secundaria do UK (2014). Fíxose unha búsqueda de materias, recursos e documentos elaborados no Estado español e en Galicia. Elaborouse un sistema de catalogación que permitirá, unha vez rematada a plataforma virtual, a busqueda atendendo a diferentes criterios: contidos, destinatarios, materias, etc.

Prevéese rematar a primeira fase da plataforma virtual en agosto, para presentala nos centros que colaboraron na investigación e recibir súas suxestións para introducir outros servicios e recursos que responsan as súas necesidades.

En canto ás personas expertas a entrevistar estaba previsto que foran catro, mais no transcurso da investigación viuse a necesidade de amplialo a 6 , en concreto a:

- Doug Bourn. Director de Development Education Research Centre-University College London

- Frances Hunt. Investigadora de Development Education Research Centre-University College London

- Vanessa Andreotti. Investi-gadora en Canada Research Chair in Race, Inequalities and Global Change. University of British Columbia (Canadá)

- Rene Suša, Estudios de Educación Global, Conocimien-to indígena y Potscolonialismo. Universidad de Oulu (Finlandia)

- Alejandra Boni, Miembro de INGENIO. Profesora de la Universidad Politécnica de Valencia

- Anna Duch, responsable de la Unidad de Educación para una ciudadanía global de Oxfam Intermón

As entrevistas foron transcritas e codificadas cun sistema aberto de identificación de dimensions e macrocategorías, de forma indutiva. Finalmente identificáronse 6 dimensións e 14 macrocategorías (Figura 2).

\begin{tabular}{|l|l|l|l|l|l|}
\hline $\begin{array}{l}\text { Educación } \\
\text { Global }\end{array}$ & $\begin{array}{c}\text { Metodo- } \\
\text { loxía }\end{array}$ & \multicolumn{1}{|c|}{$\begin{array}{c}\text { Interven- } \\
\text { ción }\end{array}$} & ONGDs & \multicolumn{1}{|c|}{$\begin{array}{c}\text { Universi- } \\
\text { dade }\end{array}$} & $\begin{array}{c}\text { Condicio- } \\
\text { nantes }\end{array}$ \\
\hline $\begin{array}{l}\text { Conceptos } \\
\text { Debate }\end{array}$ & Que é & $\begin{array}{l}\text { Centro } \\
\text { transformador }\end{array}$ & $\begin{array}{l}\text { Apoio } \\
\text { didáctico }\end{array}$ & Alumnado & $\begin{array}{l}\text { Resisten- } \\
\text { cias }\end{array}$ \\
\hline $\begin{array}{l}\text { Contidos } \\
\text { Curriculum }\end{array}$ & $\begin{array}{l}\text { Que non } \\
\text { é }\end{array}$ & Centro Nodal & $\begin{array}{l}\text { Participación } \\
\text { docente }\end{array}$ & $\begin{array}{l}\text { Formación } \\
\text { profesorado }\end{array}$ & Ventaxes \\
\hline & & Redes & & Profesorado & \\
\hline & & $\begin{array}{l}\text { Centro } \\
\text { recursos }\end{array}$ & & Investigación & \\
\hline & & & & Mestrado & \\
\hline
\end{tabular}

Figura 2. Dimensións para analizar as entrevistas a expertos.

Respecto aos centros educativos, eleximos 6 con características heteroxéneas ( 2 centros localizados en zona urbana, 2 en periurbana e 2 en contextos rurais; e respecto ás liñas educativas, 2 exclusivamente con ESO e Bacherelato, 2 con primaria e ESO e 2 con ESO, Bacherelato e Ciclos Formativos; e respecto á propiedade, 5 públicos e 1 concertado) para poder contrastar as distintas visións e as perspectivas subxectivas, fundamentais neste tipo de investigación, así como a influencia dos ambientes sociais y das características de cada contexto educativo. En cada centro entrevistáronse a 3 docentes, 18 en total, tendo en conta os tres perfis (Gráfico 3).

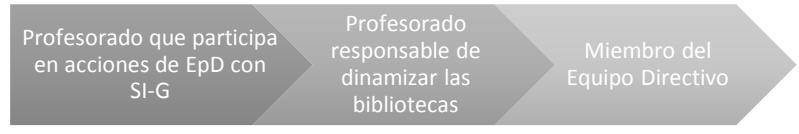

Gráfico 3. Perfil do profesorado entrevistado

Realizáronse posteriorme as transcripcións literais das entrevistas que foron codificadas cun modelo aberto para analizarse coa axuda do programa Atlas.it (Flick, 2004). En este caso identificáronse 6 dimensións e 13 macrocategorías (Táboa 3).

\begin{tabular}{|l|l|l|l|l|l|}
\hline Curriculum & $\begin{array}{l}\text { Centro } \\
\text { educativo }\end{array}$ & Profesorado & $\begin{array}{l}\text { Papel das } \\
\text { ONGDs }\end{array}$ & Biblioteca & Alumnado \\
\hline $\begin{array}{l}\text { Desenvolv. } \\
\text { Currícular }\end{array}$ & Características & $\begin{array}{l}\text { Perfil } \\
\text { docente }\end{array}$ & $\begin{array}{l}\text { Apoio } \\
\text { didáctico }\end{array}$ & Proxectos & Perfil \\
\hline $\begin{array}{l}\text { Experiencia } \\
\text { didáctica }\end{array}$ & $\begin{array}{l}\text { Comunidade } \\
\text { contorna }\end{array}$ & $\begin{array}{l}\text { Proxectos } \\
\text { de EpD }\end{array}$ & $\begin{array}{l}\text { Participación } \\
\text { docente }\end{array}$ & \\
\hline $\begin{array}{l}\text { Reformas } \\
\text { educativas }\end{array}$ & $\begin{array}{l}\text { Cultura } \\
\text { escolar }\end{array}$ & & \\
\hline $\begin{array}{l}\text { Condicionantes } \\
\text { Posibilidades }\end{array}$ & & & \\
\hline
\end{tabular}

Táboa 3. Dimensións e macrocategorías de análise

Algúns dos resultados da primeira análises foron debatidos a través dun Grupo Focal no que participaron profesorado de 3 centros e foi dinamizado por Vanessa Andreotti e Rene Susa. A transcripción tamén foi codificada atendendo ás mesmas dimensións.

Aínda non estamos en disposición de adiantar resultados porque é preciso triangular a información dispoñible, mais a modo de conslusión somos conscientes das diferencias entre UK e Galicia á hora de integrar a dimensión global no curriculum, tanto no marco legal como no que atinxe ao perfil do profesorado máis implicado (de Ciencias Sociais no primeiro caso e de materias relacionadas con valores e cidadanía no segundo). Fronte a soidade do profesorado galego á hora de participar en programas da ONGDs (o que se traduce en actividades puntuais) en UK e no resto do Estado estase a traballar en rede -ben a través de centros nodais, ou ben de centros transformadores- e é o profesorado quen deseña o material didáctico co apoio das ONGDs. Neste traballo, no que se entrelazan saberes de distintos tipos de informantes, permite debuxar de forma significativa as posibilidades de introducir a dimensión global no curriculum da ESO, identificando as cuestións máis significativas para cada grupo. A devolución dos resultados aos centros participantes permítenos continuar con procesos colaborativos e abrir novos horizontes de investigación-acción.

\section{Referencias}

Aguado, G. (coord.) (sen data). Educación para el desarrollo y la ciudadanía global. Guía para su integración en centros educativos. Interred y AECID

Andreotti, V. (2012). Development vs poverty: notions of cultural supremacy in development education policy. En D. Bourn (Ed.) Development Education. Debates and dialogues (pp. 45-63). London: Institute of Education. University of London.Argibay, M.; Celorio, G.\& Celorio, J. (2009). Educación para la ciudadanía global. Debates y desafíos. Bilbao: Hegoa.

Bourn, D. (2008.) Introduction. En D. Bourn (Ed.) Development Education. Debates and dialogues (pp. 1-17). London: Institute of Education. University of London. 
Bourn, D. \& Hunt, F. (2011). Global Dimension in Secondary Schools. London: Development Education Research Center.

Beamish, W.; Bryer, F. \& Davies, M. (2006). Teacher Reflections on Co-teaching a Unit of Work. International Journal of Whole Schooling, vol. 2, n. 2, 3-18.

Canarias, E. \& Altamira, F. (2012). Las dimensiones de análisis en Educación para el Desarrollo Educación para la Ciudadanía Global. http://iniciativasdecooperacionydesarrollo.files.wordpre ss.com/2012/10/las-dimensiones-de-la-ed-y-epcg2.pdf

CEEG-Congreso Europeo sobre Educación Global (2002). Declaración de Maastrich sobre Educación Global. http://nscglobaleducation.org/images/ Resource_center/GE_Guidelines_Spanish.pdf.

Edge, K.; Khamsi, K. \& Bourn, D. (2009) Exploring the Global Dimension in Secondary Schools. Final Research Report. Londres: The London Centre for Leadership in Learning; Institute of Education-University of London.

Flick, U. (2012). Introducción a la investigación cualitativa. Madrid: Morata.

Grotjahn, R. (1991). The research programme Subjective Theories, Studies in Second Language Acquisition, 13, pp. 187-214.

Huberman, A.M. \& Miles, M.B. (1994). Data management and analysismethods. En N.K. Denzin \& Y.S.Lincon, Handbook of Qualitative Research (Pp. 428-444). Thousand Oaks, CA: Sage. .

Hargreaves \& Fink, U. (2008). El Liderazgo Sostenible. Siete principios para el liderazgo en centros educativos innovadores. Madrid: Morata

Hicks, D. \& Holden, C. (eds) (2007). Teaching the Global Dimension: Key principles \& effective practice, London: Routledge.
Kvale, S. (2011). Las entrevistas de investigación cualitativa. Madrid: Morata.

Marshall, H. (2007). Global citizenship in the secondary school. En D. Hicks \& C. Holden, eds. Teaching the Global Dimension: Key principles and effective practice, (pp. 176-190). Abingdon, UK: Routledge Falmer.

Montero, L. (2011). El trabajo colaborativo del profesorado como oportunidad formativa. En CEE Participación educativa, n. 16, pp. 69-98.

Nussbaum, M. (2005). El cultivo de la humanidad. Una defensa clásica de la reforma en la educación liberal. Barcelona: Paidós.

Paz, D. de (2007). Escuelas y educación para la ciudadanía global: una mirada transformadora. Barcelona: Intermon Oxfam.

Polo Morral, F. (2004). Hacia un curriculum para una ciudadanía global. Barcelona: Fundación Intermon_Oxfam.

Onwuegbuzie, AJ.; Dickinson, WB.; Leech, NL. \& Zoran, AJ. (2011). Un marco cualitativo para la recolección y análisis de datos en la investigación basada en grupos focales, Paradigmas, vol. 3, n. 1, pp. 127-157.

Ruíz, JM. \& Celorio, G. (2012). Una mirada a las miradas. Los estudios de diagnóstico en Educación para el Desarrollo. Revista Interuniversitaria de Formación del Profesorado, 15, 2, pp. 79-88.

Simons, H. (2011). El estudio de caso: teoría y práctica. Madrid: Morata.

Stake, R. (1998). Investigación con estudio de casos. Madrid: Morata.

Valles, M.S. (2014). Entrevistas cualitativas. Madrid: CIS. 